\title{
Brazilian Public Health Policy for Cruise Ships - A Review of Morbidity and Mortality Rates - 2009/2015
}

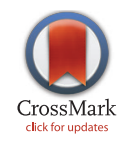

\section{Dennis Minoru Fujita ${ }^{1 *}$, Luiz Henrique da Silva Nali' ${ }^{1}$ Rita de Cassia Giraldi', Gerusa Maria Figueiredo', Heitor Franco de Andrade Júnior ${ }^{1}$}

${ }^{1}$ Instituto de Medicina Tropical de São Paulo, Universidade de São Paulo, São Paulo, Brazil

Corresponding Author: Dennis Minoru Fujita, PhD Candidate, Av. Dr. Enéas Carvalho de Aguiar, $470-2^{\circ}$ andar, CEP: 05403-000, São Paulo, Brazil. Tel:+55-11-3061-8649, Email: dmfujita@usp.br

Received August 29, 2017; Accepted September 23, 2017; Online Published October 30, 2017

\begin{abstract}
Introduction: For 10 years, Brazil has presented a significant flow in cruise ships with 597011 travelers in 2015. Cruise ships represent a major mass gathering capacity, generating more risk of outbreaks and epidemics. Moreover, visiting several places presents travelers with the possibility of contact with some tropical diseases, which demands the development of specific policies for public health surveillance. Methods: In this study, case reports on transmissible diseases, accidents and deaths on board of cruise ships in the Brazilian coast during 2009 to 2015 were reviewed and correlated with the development of public health surveillance policies implemented by ANVISA, which established the mandatory communication of infectious diseases in 2009 and of deaths onboard in 2011.

Results: Norovirus was the major etiologic agent of outbreaks, though the rate of outbreak has been declining in recent years. The lethality rate last season was 0.67:100000, mostly because of preexisting conditions (75\%); the remaining cases were caused by accidents. The mandatory reporting of outbreaks and deaths is an important tool in the planning of preventive actions for the safety and health of travelers in Brazil. The continuous evolution of hygiene surveillance may reduce outbreaks; the adoption of transparency policies and fast communication of deaths has contributed to the significant reduction in accidents.

Conclusion: The effectiveness of specific public policies for the safety and security of travelers established for cruise ships in Brazil is indicated by the quantitative reduction in outbreaks and deaths. New destinations such as Cuba and China may adopt the same strategy of surveillance and protection against potential outbreaks of infectious diseases provided by cruise ships.

Keywords: Brazil, Travelers, Outbreaks, Deaths, Cruises Ships, ANVISA
\end{abstract}

Citation: Fujita DM, da Silva Nali LH, de Cassia Giraldi R, Figueiredo GM, de Andrade Júnior HF. Brazilian public health policy for cruise ships - a review of morbidity and mortality rates - 2009/2015. Int J Travel Med Glob Health. 2018;6(1):11-15. doi:10.15171/ijtmgh.2018.03.

\section{Introduction}

According to the Cruise Line International Association (CLIA), ${ }^{1}$ there were 448 cruise ships in 2016 that transported 24.7 million travelers around the world, presenting an increase of $62 \%$ in the last 10 years $(2005 / 2015)$. This increase may be concerning for travelers considering the capacity for mass gathering in cruise ships with a high potential for infectious disease transmission. ${ }^{2}$ Allied to this is the risk involved in contact with infectious diseases at some potentially endemic locations along the vessels' routes. ${ }^{3}$

Actual cruise ships are built to carry upwards of $\sim 4000$ passengers and $\sim 1000 \mathrm{crew}$ and present at least 1 full day of navigation in their itineraries. This represents a high potential risk for the transmission of infectious diseases due to the confinement of these travelers in common spaces, with a high probability of exposure to fomites by the oscillation of the vessel. Furthermore, all internal spaces are air-conditioned. ${ }^{4}$
Cruise ships are a recent and accessible modality of travel for a considerable number of Brazilians, carrying 597011 passengers (2015) along the Brazilian coast. This figure represents the ninth highest number of cruise travelers in the world. ${ }^{5}$

Reporting cases and outbreaks is a mandatory measure of surveillance and control on ships; it is meant to prevent the importation of infectious diseases between locations and possibly to control the potential spread, which in Brazil, are the responsibility of the Agência Nacional de Vigilância Sanitária - ANVISA.

Considering that infectious diseases may represent a concern during travel season along the Brazilian coast, the current study assessed the cases of infectious diseases that occurred from the year 2009, when the mandatory notification was established by the Brazilian government, through 2015 to identify the main causes of morbidity and deaths along the

Copyright ( $\odot 2018$ The Author(s). This is an open-access article distributed under the terms of the Creative Commons Attribution License (http:// creativecommons.org/licenses/by/4.0), which permits unrestricted use, distribution, and reproduction in any medium, provided the original work is properly cited. 
Brazilian coast.

The incidence of reported cases was correlated to the main surveillance measures adopted by year, and the efficiency of these policies, such as the transparency communication policy, was analyzed to possibly suggest new actions to improve local public health policies.

\section{Methods}

The operational procedures of public health surveillance in Brazil were originally established by Resolution DC/ANVISA No23 of February 6, 2003. They were extended by RDC No81 of November 5, 2008 from the Board of Directors (Rules on Regulation: Technical Goods and Imported Products for Health Surveillance Purposes) and consolidated by the Board of Directors with RDC $\mathrm{N}^{\circ} 72$ of December $29,2009 .^{6}$

Thus, this study began with cases from 2009. Three main periods of analysis were chosen according to the evolution of the notification system for occurrences and deaths: In the $2009 / 2010$ season, the establishment of mandatory notification of cases; in the 2010/2011 season, the implementation of mandatory death notification; and in the 2011/2012 season, the update of the mandatory notification of cases with daily reports.

Morbidity and mortality rates per season on cruise ships in Brazil from 2009 to 2015 were accessed through official reports and electronic communication provided by ANVISA and technical reports of the Brazilian Ministry of Health. The main Brazilian resolutions established in this period for the inspection and supervision of disease and mortality control in vessels were analyzed.

This research followed the framework for compulsory notification of suspected cases - acute diarrheal disease (DDA), flu syndrome (GS), Cholera, Botulism, Polio, exanthematous diseases, meningitis, and other diseases - established by ANVISA. ${ }^{7}$ Outbreaks were considered according to the parameters in cases of communicable diseases caused by rare agents, of which only one event can be considered as outbreak (e.g., botulism, cholera, polio, measles, etc); however, the declaration of an acute diarrheal outbreak was considered when the number of cases presenting a compatible frame reached or exceeded $2 \%$ of the travelers or crew.

Routine notification includes other cases onboard such as occupational accidents, throat inflammation, allergies, cardiovascular problems, etc.

\section{Results}

The total number of travelers on cruises in Brazil has increased in the last 10 years (Figure 1A). The reduction in mass capacity in the last 3 seasons is due to the increased number of days in route (from 3-4 days to 7-11 days) as well as in total duration started in the 2011/2012 season with one month less than the previous period.

Usually, most cruise travelers in Brazil are women (55.8\%). The predominant age group is between 25 and 44 years (48.6\%). The mean age of Brazilians who choose cruises is lower than that of travelers to destinations in Europe and the United States.

Most travelers have a college degree (58.1\%), and $14.7 \%$ have a monthly household income of over \$3000 USD. Currently, the largest group of travelers consists of young people and families. Cruises of 7 nights or more are generally for family groups and attract people with higher incomes.

The development of policies for the safety and inspection of passenger vessels in Brazil accompanied the evolution in regards to the cruise market development by a quantitative increase in the number of travelers and ships in the Brazilian Coast, taking up the application of strict guidelines by Brazilian authorities according to the following data (Table 1):

In the 2009/2010 season, 4441 cases of sick travelers or crew members were reported. One ship experienced 2 outbreaks in the same season (348 travelers in the first event and 60 in the second).

In the 2010/2011 season, the number of reported cases dropped to 792 , a reduction of $82 \%$. This figure is still worrying, especially the number of cases of Influenza B (H1N1 - $n=297$ ); one specific ship registered travelers and crew with flu-like symptoms (50 cases of respiratory syndrome-flu and 30 cases of acute diarrhea). Samples were collected for analysis and identified to determine if the events were sector (single-site) or uniform in vessel; the landing of tourists was not authorized on arrival (quarantine).

During the 2011/2012 season, the implementation of the Brazilian Sanitary Guide for Cruise Ships and other measures such as the mandatory death report and the new online form may explain the low number of reports $(n=108)$. Influenza $B$ was the second main cause of notification $(n=50)$. Only 1 death by influenza B was reported in this season (Table 2).

In the 2012/2013 season, $82 \%$ of notifications were related to acute diarrheal disease ( $n=455$ cases). Special attention was given to one ship that presented 2 outbreaks of gastroenteritis. The first account of outbreak reported 19 afflicted travelers and crew members (considered low risk), and the second occurrence reported 310 and 38 confirmed cases of norovirus among cruise travelers and crew members, respectively. The second most reported disease was severe flu illness with $14.6 \%$. In this season, the health teams onboard were required to notify the medical calls, reporting even the absence of cases. The number of deaths increased to 8 (lethality rate $-1.09: 100000$ ) with the main causes being accidents (50\%), followed by pre-existing conditions (37.5\%), such as myocardial infarction $(n=2)$ and leukemia $(n=1)$.

In the $2013 / 2014$ season, notifications increased $47.8 \%$ $(\mathrm{n}=819)$ with $90.3 \%$ of cases related to acute gastroenteritis $(n=284)$ caused by norovirus. Influenza B persisted $(n=43)$, but there was a decrease in Varicella (from $n=9$ to $n=4$ ). Only 3 deaths were reported with a decrease in the number of accidents $(n=1)$.

In the 2014/2015 season, the number of passengers decreased $(7.78 \%)$, and accompanying this result was a significantly reduced number of notifications $(n=548)$. Acute gastroenteritis was still the main cause with $60 \%(n=91-$ caused by norovirus), followed by acute flu. Three deaths by myocardial infarction and 1 death by drowning were reported, indicating that pre-existing condition was still a problem.

The final framework of morbidity in cruise ships along the Brazilian coast is analyzed in Figure 1B, which explains the 

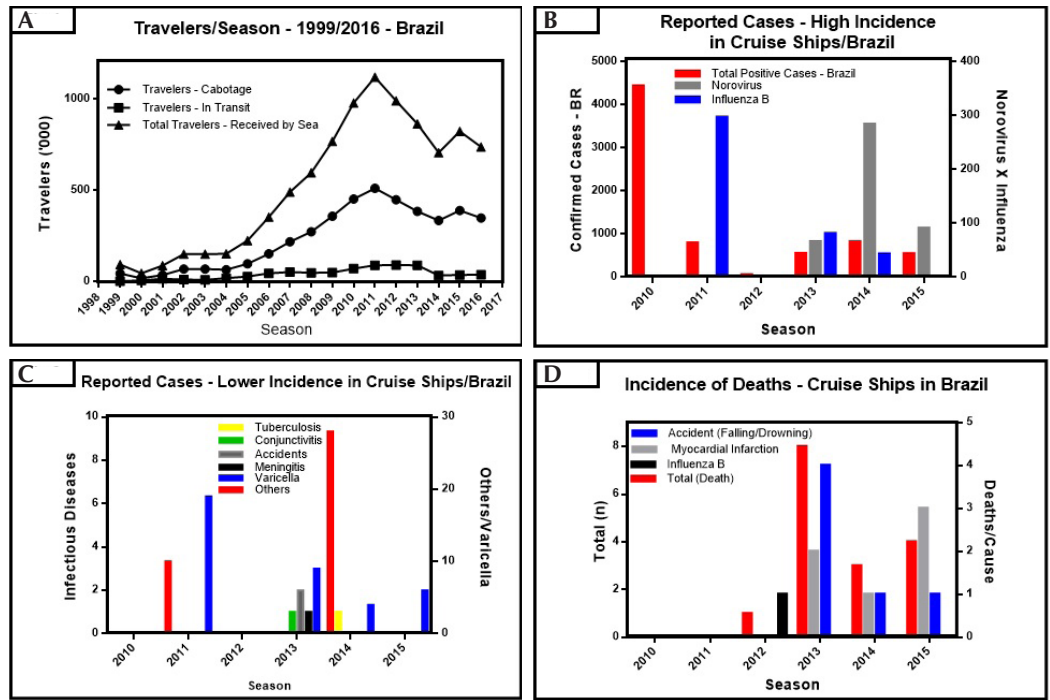

Figure 1. Morbidity and Mortality Rates - 2009/2015.

controlled framework of outbreaks after 2010 when the rules and norms became more severe for supervision of food and water quality.

The mandatory reporting of deaths onboard adopted in 2011 resulted in an increase in reported cases in the 2012/2013 season (Figure 1C). Previously, cases were reported only at the docking sites of the cruise line and not on ships at sea. The most severe cases were usually transferred to service ashore, because the vessels engaged during the Brazilian cruise season are equipped with only the basic framework for first aid and patient stabilization (Figure 1D).

\section{Discussion}

New guidelines have been continuously redesigned since 2009, with reports of medical cases and outbreaks formulated annually by ANVISA; some information is available to the public, such as quality reports of hygiene from ships and even technical information like morbidity and mortality rates per season. ${ }^{9}$

The beginning of mandatory case report in the 2009/2010 season resulted in a higher number of confirmed cases $(\mathrm{n}=4441)$, but no description of the diseases was available.

In the $2010 / 2011$ season, $\sim 30 \%$ of cruise ships that arrived in the country had reports of notifiable diseases, accidents and deaths, with the main irregularities related to water quality and its storage as well as the preparation and distribution of food which increased the norovirus contamination risk factors, one of the most common problems in ships according to CDC data. ${ }^{10}$ For this reason, $38 \%$ of reported cases of illness were of acute diarrhea, and the main agent was norovirus usually transmitted through the ingestion of contaminated food/water.

Influenza B was the second most important infectious disease aboard the ships, ${ }^{8}$ and it was treated by fast hospitalization of suspect cases (isolated and monitored). Quarantine was applied on 1 ship (travelers and crew members were vaccinated for influenza).

Only 1 death was reported to ANVISA, due to data from notifiable institutionalization of deaths that occurred only in early 2012. In most cases, the occurrence was transferred to the first port of call and was not considered as a situation onboard.

Preliminary data on outbreaks suggests that measures adopted to reduce morbidity such as the control of onboard water quality and the institutionalization of supply standards for food and beverage were important (Figure 1C). The decrease in the number of travelers and vessels each season as well as the institutionalization of an "all inclusive" policy for food and beverage onboard which reduced external consumption and allowed a controlled framework on Brazilian cruise ships. ${ }^{11}$

The occurrences can be decreased with preventive actions

Table 1. Case Reports - Cruise Ships - Brazil - 2009/2015

\begin{tabular}{|c|c|c|c|c|c|c|c|c|c|c|c|}
\hline Season & Confirmed Cases - BR & Acute Gastroenteritis & Norovirus & Influenza B & Varicella & Meningitis & Accidents & Conjunctivitis & Tuberculosis & Others & False \\
\hline $2009 / 2010$ & 4441 & & & & & & & & & & \\
\hline $2010 / 2011$ & 792 & 466 & 0 & 297 & 19 & 0 & 0 & 0 & 0 & 10 & 0 \\
\hline $2011 / 2012$ & 58 & 58 & 0 & 0 & 0 & 0 & 0 & 0 & 0 & 0 & 0 \\
\hline $2012 / 2013$ & 554 & 455 & 66 & 81 & 9 & 1 & 2 & 1 & 0 & 0 & 5 \\
\hline $2013 / 2014$ & 819 & 740 & 284 & 43 & 4 & 0 & 0 & 0 & 1 & 28 & 3 \\
\hline
\end{tabular}

*NA, data not available. 
Table 2. Mortality - Cruise Ships - Brazil - 2009/2015

\begin{tabular}{|c|c|c|c|c|c|c|c|}
\hline Season & Mortality & Myocardial Infarction & Accident (Falling/Drowning) & Influenza B & Pulmonary Edema & Leukemia & Unknown \\
\hline $2009 / 2010$ & NA & & & & & & \\
\hline $2010 / 2011$ & NA & & & & & & \\
\hline $2011 / 2012$ & 1 & 0 & 0 & 1 & 0 & 0 & 0 \\
\hline $2012 / 2013$ & 8 & 2 & 4 & 0 & 1 & 1 & 0 \\
\hline $2013 / 2014$ & 3 & 1 & 1 & 0 & 0 & 0 & 1 \\
\hline $2014 / 2015$ & 4 & 3 & 1 & 0 & 0 & 0 & 0 \\
\hline
\end{tabular}

*NA, data not available.

such as the communication of situations by season and making people aware of those problems. Preventive actions should allow guidelines to reduce risks, uniting policies between the private (maritime cruise owners) and the public sectors (ANVISA) in order to better prepare both the crew and the travelers.

The existence of short routes ( 3 to 4 -day cruises) during the $2012 / 2013$ season was a problem to outbreak control and supervision, for the most usual cruise diseases had a greater incubation time than the duration of the trip itself. Diagnosis often occurs only after the trip and usually at the traveler's place of residence; thus, it is not reported through the notification process to ANVISA and no action is taken on the vessels. In these cases, it is important to create a tracking and monitoring mechanism to obtain an overall picture. This season registered a considerable number of deaths $(\mathrm{n}=8-1.09: 100000) 1$ year after the formal establishment of mandatory reporting.

Brazil still maintained a considerable incidence rate for infectious disease in 2015 (99.70:100000), but presents a continuous decrease in outbreaks and improved epidemiological contention arising from more effective preventive actions and monitoring undertaken in recent years (137.42:100000 in 2014). However, due to the mandatory notification in cases of death in the country, despite the fact that occurrences are unfavorable (0.73:100000 in 2015), it may be suggested that the Brazilian model has had an impact on the control process and on monitoring by creating the possibility of creating a risk map and actions for prevention. For example, the number of deaths caused by accidents reduced $75 \%$ from 2013 to 2015 with a decrease in incidence rate $(0.18: 100000)$.

In Brazil, travelers' accidents resulting in death were caused by two factors: the excessive consumption of alcoholic beverages and many unprotected outdoor areas leading to falls overboard. The reduction in the number of deaths was obtained by adopting the transparency policy strategy with massive media information and awareness measures to guide travelers to avoid such situations, especially in cases of accident, as travel health advisories, as took place in other countries. ${ }^{12}$

Deaths caused by pre-existing conditions increased in the last 3 years, requiring the closer attention of travelers to individual health conditions. The last death related to an infectious disease was reported in 2011/2012 and was caused by influenza $B$, under pandemic flu conditions. It was well controlled and managed in Brazil considering the mass gathering situation provided in cruise ships. ${ }^{13}$

In case of a norovirus outbreak, it is mandatory to promote public awareness (travelers and crew) of the potential problems in external food services, especially at docking sites due to the lack of appropriate hygienic conditions and preparation of goods inland.

Nevertheless, the mandatory reporting of death has generated effective measures for the public and provided clear information that changed travelers' behaviors onboard. Moreover, new internal policies were developed for cruises to prevent such situations, and this was an extremely positive effect.

It is noteworthy that with the current issue of quality, cruise ships in Brazil have the same general level of health security that the world's leading cruise destinations have, but with even more rigorous rules than countries with a longer tradition. ${ }^{14,15}$

\section{Conclusion}

The effectiveness of the specific public health policies for the safety and security of travelers established for cruise ships on the Brazilian coast is suggested by the quantitative reduction in outbreaks in the last few years. Reporting occurrences onboard and public access can be excellent tools for planning and maintaining the welfare of travelers, because public knowledge of data might generate awareness, such as a transparency policy. New destinations like Cuba and China arose in 2016; such destinations will need to develop their own public health policies for surveillance and protection against potential outbreaks of infectious diseases aboard cruise ships, ${ }^{16}$ a steady work that has taken place in Brazil.

\section{Authors' Contributions}

All authors significantly contributed towards this study.

\section{Conflict of Interest Disclosures}

The authors state they have no conflicts of interest to declare.

\section{Ethical Approval}

This study was approved by the Research Ethics Committee FMUSP-HC System - Process: CAAE 22239713.0.0000.0065

- Technical Report No 420.882 issued on October 09, 2013.

\section{Funding/Support}

None. 


\section{Acknowledgments}

The authors wish to acknowledge the assistance recieved from Instituto de Medicina Tropical de São Paulo - USP, LIM - 49 / LIM - 52 - HCFMUSP, FAPESP and CAPES.

\section{References}

1. CLIA. 2017 Cruise Industry Outlook. https://www.cruising.org/ docs/default-source/research/clia-2017-state-of-the-industry. pdf?sfvrsn=0. Accessed 2016

2. Pavli A, Maltezou HC, Papadakis A, et al. Respiratory infections and gastrointestinal illness on a cruise ship: A three-year prospective study. Travel Med Infect Dis. 2016;14(4):389-397. doi:10.1016/j. tmaid.2016.05.019.

3. Rodriguez-Morales AJ, Schlagenhauf P. Zoonoses and travel medicine: "one world--one health". Travel Med Infect Dis. 2014;12(6 Pt A):555-556. doi:10.1016/j.tmaid.2014.11.003.

4. Kak V. Infections on Cruise Ships. Microbiol Spectr. 2015;3(4). doi:10.1128/microbiolspec.IOL5-0007-2015.

5. ABREMAR. Temporada de Navios de Cruzeiros 2015. http:// abremar.hospedagemtemporaria.com.br/temporadas-2/. Accessed August 8, 2016.

6. Brazil. Brazilian Health Legislation Data Bank 2015. ANVISA. http://portal2.saude.gov.br/saudelegis/LEG_NORMA_PESQ_ CONSULTA.CFM. Accessed October 26, 2014.

7. ANVISA. Temporada de Navios de Cruzeiros. http://www.anvisa. gov.br/hotsite/cruzeiros/industria.html.
8. Fernandes EG, de Souza PB, de Oliveira ME, et al. Influenza B outbreak on a cruise ship off the Sao Paulo Coast, Brazil. J Travel Med. 2014;21(5):298-303. doi:10.1111/jtm.12132.

9. Cruise Ships Season - Anvisa. http://www.anvisa.gov.br/hotsite/ cruzeiros/industriaingles.html. Accessed July 24, 2017.

10. CDC. CDC - Vessel Sanitation Program. http://www.cdc.gov/nceh/ vsp/. Accessed March 20, 2016.

11. Mouchtouri VA, Nichols G, Rachiotis G, et al. State of the art: public health and passenger ships. Int Marit Health. 2010;61(2):49-98.

12. Marchand C, Merrina F, Gagnayre R, Bouchaud O. A descriptive study of advising practices during travel health consultations in France. J Travel Med. 2017;25(5):582-602. doi:10.1093/jtm/ tax042.

13. Goeijenbier M, van Genderen P, Ward BJ, Wilder-Smith A, Steffen $R$, Osterhaus AD. Travellers and influenza: risks and prevention. J Travel Med. 2017;24(1):taw078. doi:10.1093/jtm/taw078.

14. Oldenburg M, Herzog J, Püschel K, Harth V. Mortality of German travellers on passenger vessels. J Travel Med. 2016;23(1). doi:10.1093/jtm/tav003.

15. Lawson CJ, Dykewicz CA, Molinari NA, Lipman H, Alvarado-Ramy F. deaths in international travelers arriving in the United States, July 1, 2005 to June 30, 2008. J Travel Med. 2012;19(2):96-103. doi:10.1111/j.1708-8305.2011.00586.x.

16. Mitruka K, Felsen CB, Tomianovic D, et al. Measles, rubella, and varicella among the crew of a cruise ship sailing from Florida, United States, 2006. J Travel Med. 2012;19(4):233-237. doi:10.1111/j.1708-8305.2012.00620.x. 